\title{
REVISIÓN
}

\section{$\beta$-glucanos, su producción y propiedades en microalgas con énfasis en el género Nannochloropsis (Ochrophyta, Eustigmatales)}

\author{
$\beta$-glucans, production and properties in microalgae with emphasis \\ on Nannochloropsis genus (Ochrophyta, Eustigmatales)
}

\section{Diego Espinoza-Gallardo ${ }^{1}$, Loretto Contreras-Porcia ${ }^{2,3}$ y Nicole Ehrenfeld ${ }^{1 *}$}

\author{
${ }^{1}$ Centro de Investigación AustralBiotech, Universidad Santo Tomás, Av. Ejército 146, Santiago, Chile. *nicole.ehrenfeld@ australbiotech.cl \\ ${ }^{2}$ Departamento de Ecología y Biodiversidad, Facultad de Ecología y Recursos Naturales, Universidad Andres Bello, República 440, \\ Santiago, Chile \\ ${ }^{3}$ Center of Applied Ecology \& Sustainability (CAPES), Pontificia Universidad Católica de Chile, Av. Libertador Bernardo O’Higgins \\ 340, Santiago, Chile
}

\begin{abstract}
Microalgae are photosynthetic eukariotic microorganisms capable of producing a wide range of compounds of commercial interest, such as vitamins, antioxidants, omega-3 fatty acids, and immunostimulants like $\beta$-glucans. $\beta$-glucans are Dglucose polymers linked by $\beta-1,3$ and/or $\beta-1,4$ bonds, which can present branches of $\beta-1,6$ bonds. The most well known in microalgae are the paramylon (in euglenoids) and the chrysolaminarin (in diatoms). In the genus Nannochloropsis, (Ochrophyta), the genome and transcriptome sequencing of species has shown that they are also likely to be able to synthesize $\beta$-glucans with $\beta-1,3$ bonds with $\beta-1,6$ side branches. There are few studies about these $\beta$-glucans in those species but it is suggested that they are carbon/energy-storage molecules that replace starch and perform similarly to storage lipids such as triacylglycerol (TAG), competing for the same precursor molecules produced by the carbon fixation. The presence of $\beta$-glucans, along with characterizing them and confirming their beneficial properties for human health, could grant a high potential to the culture of Nannochloropsis with commercial purposes. These cultures have already gained great interest because of their high contents of TAG used to produce biodiesel or eicosapentanoic acid (EPA) to feed rotifers, fish or for nutraceutical purposes in humans. The objective of this review is to describe the properties of $\beta$-glucans in microalgae and the potential use of Nannochloropsis in the production of these molecules.
\end{abstract}

Key words: Microalgae, nutraceutics, $\beta$-glucans, Nannochloropsis

\begin{abstract}
Resumen.- Las microalgas son microorganismos eucariontes fotosintéticos capaces de producir una amplia gama de compuestos de interés comercial, tales como vitaminas, antioxidantes, ácidos grasos omega-3 e inmunoestimulantes como los $\beta$-glucanos. Los $\beta$-glucanos son polímeros de D-glucosa unidos por enlaces $\beta-1,3$ o $\beta-1,4$ los cuales pueden presentar ramificaciones de enlaces $\beta-1,6$. Los más conocidos en microalgas son el paramilón (presente en euglenoides) y la crisolaminarina (presente en diatomeas). En el género Nannochloropsis, (Ochrophyta), la secuenciación de los genomas y los transcriptomas de algunas de sus especies ha evidenciado que también serían capaces de sintetizar $\beta$-glucanos de enlaces $\beta-1,3$ con ramificaciones $\beta-1,6$. Si bien, existen pocos estudios con respecto a dichos compuestos en estas especies, se sugiere que corresponderían a moléculas de reserva energética de carbono, que reemplazan el almidón y que presentan un comportamiento similar al de los lípidos de reserva como el triacilglicerol (TAG). Por lo que, puden competir por las mismas moléculas precursoras derivadas de la fijación de carbono. La presencia de los $\beta$-glucanos junto con su caracterización y la validación de sus propiedades beneficiosas para la salud humana, pueden otorgar un potencial interés económico al cultivo de Nannochloropsis. Estos cultivos, han adquirido un enorme interés debido a su alto contenido de TAG para la producción de biodiesel o ácido eicosapentanoico (EPA) para la alimentación de rotíferos, peces y humanos con fines nutracéuticos. Esta revisión tiene como finalidad evidenciar las propiedades de los $\beta$-glucanos en microalgas y el uso potencial de Nannochloropsis en la producción de esas moléculas.
\end{abstract}

Palabras clave: Microalgas, nutracéuticos, $\beta$-glucanos, Nannochloropsis

\section{INTRODUCCIÓN}

Las algas, son un grupo extremadamente diverso de organismos eucariontes, en su mayoría autotróficas, aunque también pueden ser mixotróficas y heterotróficas (John 1994, van den Hoek et al.1995). Estos organismos pueden abarcar desde microorganismos unicelulares hasta organismos multicelulares (Bold \& Wynne 1985), y se estima que realizan aproximadamente el $50 \%$ de la fotosíntesis del planeta (John 1994), siendo organismos fundamentales para la existencia y 
mantención de la biosfera. Las microalgas han sido sujeto de gran interés en los últimos 10 años debido a sus altas tasas de crecimiento en condiciones favorables, pudiendo afectar el medio ambiente a través de proliferaciones masivas (blooms en inglés, i.e., rápido incremento en la población algal de un sistema acuático; Kim et al. 2015) o ser utilizadas para la producción de productos de interés comercial, como biocombustibles, aditivos alimenticios, compuestos nutracéuticos, entre otros (Apt \& Behrens 1999). El elevado crecimiento de estos organismos, se sustenta en su alta eficiencia en la fijación de $\mathrm{CO}_{2}$, utilización de fuentes de carbono orgánicas, nitrógeno y fosfatos inorgánicos y orgánicos, entre otros (Borowitzka 1999). Estos organismos han sido capaces de colonizar diferentes tipos de hábitats, incluyendo todo tipo de ambientes acuáticos, terrestres e inclusive ambientes extremos como el desierto de Atacama (van den Hoek et al. 1995, Azua-Bustos \& González-Silva 2014).

Dada su alta flexibilidad metabólica, ha sido posible cultivar a nivel mundial microalgas a gran escala mediante fotobiorreactores y en panel (indoor u outdoor) y piscinas al aire libre del tipo raceway. Así, el cultivo de microalgas se propone como una fuente de producción sustentable para una amplia gama de productos bioquímicos, como fármacos, aditivos alimenticios, suplementos alimenticios, alimentación para animales, como también biocombustibles y compuestos nutracéuticos (Borowitzka 1999, Richmond 2000, AdarmeVega et al. 2012, Yen et al. 2014).

Los nutracéuticos corresponden a compuestos cuyo consumo se ha relacionado con la prevención y/o el tratamiento de ciertas enfermedades y como complemento de fármacos (Kalra 2003, Valenzuela et al. 2014). Chile aún no cuenta con una definición formal sobre nutracéutico ni alimento funcional en la normativa alimentaria vigente (Reglamento Sanitario de los Alimentos), aunque la industria de alimentos utiliza con frecuencia el término alimento funcional para identificar a productos que tienen adicionado mayor cantidad de un componente naturalmente presente en el alimento, $o$ al que se le adiciona uno o más componentes no presentes naturalmente en el producto (Valenzuela et al. 2014). Para el caso de algunos de estos compuestos, la evidencia científica sobre los beneficios en la salud humana es tan sólida y reconocida por la comunidad científica internacional, que sus componentes han sido avalados por agencias reguladoras gubernamentales, como el FDA de los Estados Unidos, la Agencia Alimentaria de la Unión Europea oel Ministerio de Salud y Bienestar Social de Japón (Valenzuela et al. 2014). Existen alrededor de 470 nutracéuticos y alimentos funcionales comercialmente disponibles con investigaciones que respaldan sus beneficios para la salud, los cuales contaron con un tamaño de mercado global estimado de 142,1 billones de dólares en el 2011 principalmente en Estados Unidos, Japón y Europa, y un potencial crecimiento a corto plazo. Dichos compuestos pueden ser producidos por microalgas, entre los cuales se puede encontrar las vitaminas A (retinol), B1 (tiamina), B2 (riboflavina), B3 (niacina), B6 (piridoxina), B9 (ácido fólico), B12 (cobalamina), C (ácido ascórbico), D, E (tocoferol) y H (biotina). También se reportan altas cantidades de minerales y elementos esenciales como hierro, zinc, yodo, calcio, entre otros (Bishop \& Zubeck 2012).

Además, las microalgas son productores de aminoácidos, antioxidantes (como la astaxantina) y ácidos grasos esenciales, como omega 6 (ácido araquidónico) y los ácidos grasos omega3: ácido alfa linolénico (ALA), eicosapentaenoico (EPA) y docosahexaenoico (DHA), que presentan mejor biodisponibilidad y características organolépticas que los provenientes del pescado (Adarme-Vega et al. 2012). Además, se ha descrito que estos microorganismos, junto con algunas macroalgas, serían capaces de producir compuestos inmunoestimulantes como los $\beta$-glucanos (Bishop \& Zubeck 2012).

\section{1. $\beta$-gluCANOS: POTENCIAL COMO NUTRACÉUticos Y ORGANISMOS PRODUCTORES}

Los $\beta$-glucanos son un grupo heterogéneo muy diverso de polisacáridos conformados por monómeros de D-glucosa unidos mediante enlaces glicosídicos tipo $\beta$ (Stone \& Clarke 1992). Estos polisacáridos pertenecen a un grupo de compuestos fisiológicamente activos denominados modificadores de la respuesta biológica, debido a su capacidad de interactuar con el sistema inmune de vertebrados e incluso invertebrados (Werner 1987, Novak \& Vetvicka 2009). La gran diversidad de estas moléculas se debe en parte, a las diferencias en la proporción y disposición de sus enlaces glicosídicos $(\beta-1,3, \beta-1,4$ y $\beta-1,6)$, donde en la mayoría de los casos se presentan como una cadena principal de longitud variable (enlaces $\beta-1,3$ y/o $\beta-1,4$ ) con ramificaciones laterales de cadenas de D-glucosa unidas por enlaces $\beta-1,4$ y $\beta-1,6$ (Stier et al. 2014). Los $\beta$-glucanos han sido descritos previamente en bacterias, hongos, levaduras (incluyendo la levadura de cerveza), plantas y algas, donde cumplen un importante rol estructural en la pared celular o de reservorio energético (Brownfield et al. 2009, Bulone 2009, Nogami \& Ohya 2009).

Existen más de 6000 estudios que han descrito los efectos inmuno-modulatorios de $\beta$-glucanos, principalmente los de enlaces $\beta-1,3$, tales como propiedades anti-inflamatorias y antimicrobianas (Vetvicka \& Vetvickova 2010), junto con otros efectos beneficiosos para la salud, como hepatoprotectores, 
sanación de heridas, pérdida de peso, propiedades antidiabéticas y la disminución del colesterol sanguíneo (Zekovic et al. 2005, Vetvicka \& Vetvickova 2011). Estas propiedades han sido reportadas tanto en humanos como en animales, incluyendo animales de granja, roedores, peces e invertebrados (Novak \& Vetvicka 2009), dando cuenta de su alto potencial de desarrollo y sus múltiples aplicaciones. Esta capacidad de interactuar con el sistema inmune de diversos organismos se relacionaría al reconocimiento e interacción con receptores de membrana de monocitos, neutrófilos, macrófagos, células asesinas naturales, eosinófilos, células epiteliales alveolares, células endoteliales y fibroblastos, entre otros tipos celulares (Brown \& Williams 2009). Al menos 4 receptores han sido identificados en mamíferos para el reconocimiento de estas moléculas: lactosilceramida, receptores basurero (scavengers), receptor del complemento 3 y dectina-1 (Brown $\&$ Williams 2009). Estudios en dectina-1 han demostrado que este sería el principal receptor de 1,3- $\beta$-glucanos en leucocitos y que la unidad mínima de reconocimiento es un polisacárido de entre 8 a 11 unidades de glucosa unidas por enlaces $\beta-1,3$ con una sola ramificación (Brown \& Williams 2009). Además, este receptor sería incapaz de interactuar con otras moléculas como el manano o la celulosa.

Se ha llevado a cabo producción comercial de 1,3- $\beta$ glucanos mediante el cultivo de bacterias, levaduras, hongos y plantas. Por ejemplo, el curdlano, un $\beta$-glucano lineal de enlaces $\beta-1,3$ sin ramificaciones (Fig. 1) es sintetizado por especies de Agrobacterium y Alcaligenes faecalis bajo condiciones donde el nitrógeno es limitante (Lee et al. 1997). Este compuesto es utilizado principalmente como material gelificante para mejorar la textura, la capacidad de retención de agua y la estabilidad térmica de alimentos. Existen varios reportes sobre la actividad biológica de este tipo de $\beta$-glucano de origen bacteriano (Kim et al. 2003). Por ejemplo, Jagodzinski et al. (1994) reportaron que el sulfato de curdlano poseía gran actividad anti-VIH, además de presentar bajos efectos secundarios. Mikio et al. (1995) encontraron que un derivado de curdlano, modificado mediante una reacción con glicidol, desarrolló una excelente actividad antiviral con una toxicidad extremadamente baja. Incluso, se ha sugerido que el curdlano podría ser un tratamiento auxiliar potencial contra la malaria (Evans et al. 1998).

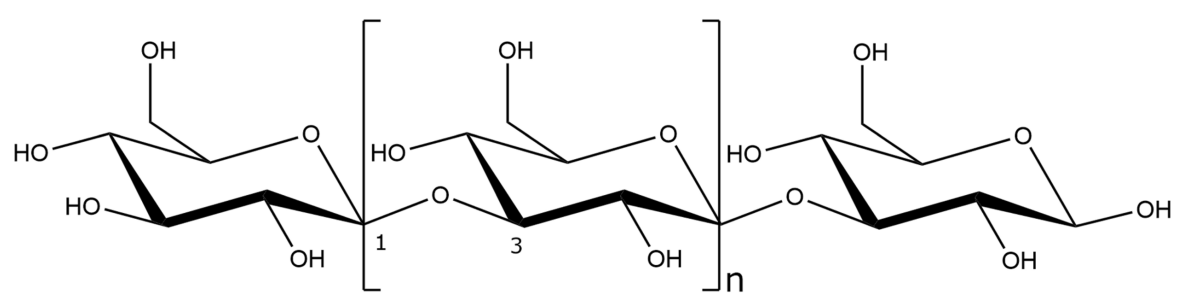

Figura 1. Estructura de 1,3- $\beta$-glucano lineal no ramificado como paramilón o curdlano / Structure of not branched lineal $1,3-\beta$-glucan like paramilon or curdlan

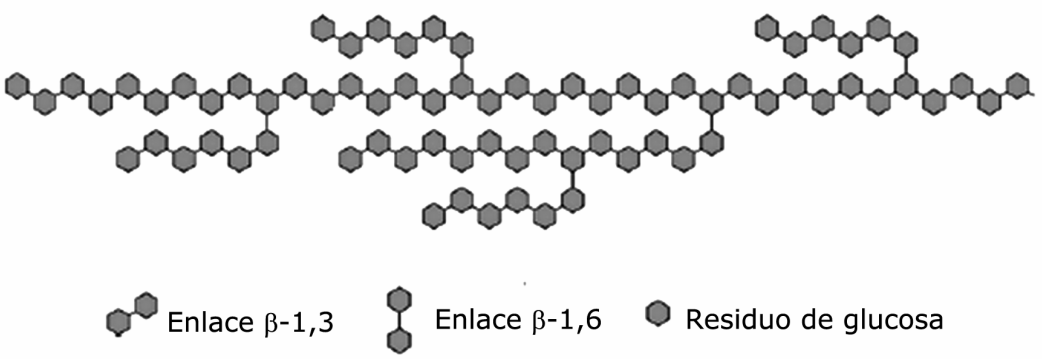

Figura 2. Estructura simplificada del 1,3;1,6- $\beta$-glucano de la pared celular de Saccharomyces cerevisiae / Simplified structure of 1,3;1,6- $\beta$-glucan from Saccharomyces cerevisiae cell wall. 
En hongos los $\beta$-glucanos son un componente estructural de la pared celular, donde predominan los 1,3- $\beta$-glucanos lineares de alto peso molecular. Están conformados por alrededor de 1500 residuos de glucosa con ramificaciones de cadenas más cortas, que van unidas a la cadena principal por enlaces $\beta$-1,6 (Fig. 2). Estos $\beta$-glucanos se unen mediante enlaces covalentes a otras moléculas estructurales de la pared, como quitina (mediante enlaces glicosidicos $\beta-1,4$ ) y proteínas, estas últimas unidas a cadenas de 1,6- $\beta$-glucano por medio de un anclaje glicosilfosfatidilinositol o a la cadena de 1,3- $\beta$ glucano mediante enlaces éster (Kapteyn et al. 1999, Nogami \& Ohya 2009). En las levaduras, los glucanos son el mayor componente filamentoso de la estructura de la pared celular, donde llegan a formar cerca del $50 \%$ del peso seco de la pared de Saccharomyces cerevisiae (Nogami \& Ohya 2009).

Los $\beta$-glucanos de origen fúngico, especialmente los producidos por la levadura de cerveza, han sido ampliamente descritos con efectos inmuno-modulatorios (Bohn \& BeMiller 1995), encontrándose además múltiples propiedades tales como actividad antitumoral (Chihara et al. 1970), actividad anti-fúngica/anti-bacteriana (Onderdonk et al. 1992), entre otras. Si bien la mayoría de los estudios realizados en hongos han sido llevados a cabo con $\beta$-glucano de levadura (Saccharomyces cerevisiae), investigaciones en otras especies han logrado desarrollar algunas drogas anti-cancerígenas en base a $\beta$-glucano, tales como Krestin (Grifola frondosa) (Nakazato et al. 1994, Maehara et al. 2012), Lentinan (Lentinula edodes) (Zhang et al. 2011) y Schizophyllan (Schizophyllum commune) (Mansour et al. 2012).

En plantas, el tipo más común de $\beta$-glucano es la celulosa, formada por cadenas de glucosa de enlaces $\beta-1,4$ que no presenta efectos inmunomodulatorios (McFarlane et al. 2014). Algunos cereales como la avena y la cebada, son capaces de producir $\beta$-glucanos no ramificados de enlaces mixtos $\beta-1,3$ y $\beta-1,4$ (Fig. 3), los cuales han atraído gran interés en investigación debido a su capacidad de interactuar con el sistema inmune de vertebrados (Xia et al. 1999, Tada et al. 2009), potenciar la acción probiótica de bacterias benéficas (MetzlerZebeli \& Zebeli 2013, Arena et al. 2014), inducir posibles efectos positivos contra el colesterol y la obesidad (Lin et al. 2013), así como mejorar el rendimiento al realizar actividad física (Xu et al. 2013). Otro tipo de $\beta$-glucano que está presente en plantas es la callosa, que presenta 1,3 - $\beta$-glucano lineal no ramificado formando parte de tejidos de plantas embriofitas en paredes celulares especializadas o en estructuras asociadas a pared en etapas particulares de diferenciación (Stone 2009). También, se encuentra presente como depósitos discretos en la pared celular inducidos por heridas, estrés fisiológico o patológico (Stone 2009).

Las algas son capaces de producir este tipo de moléculas. En macroalgas pardas, por ejemplo, se puede encontrar la laminarina, que es un 1,3;1,6- $\beta$-glucano de reserva acumulado al interior de vacuolas (Bulone 2009). A continuación, se describirá en detalle los principales tipos de 1,3- $\beta$-glucanos presentes en microalgas y las ventajas productivas de estos organismos.

\section{1,3- $\beta$-GLUCANOS EN MiCROALGAS}

En microalgas, la producción comercial de 1,3- $\beta$-glucanos no ha sido desarrollada en extenso. Estos polisacáridos son sintetizados y acumulados como carbohidratos de reserva en las divisiones Ochrophyta, Haptophyta y Euglenophyta, reemplazando al almidón y compitiendo con los lípidos por los mismos precursores provenientes de la fijación de carbono (van den Hoek et al. 1995). Los 1,3- $\beta$-glucanos en algas son almacenados en vacuolas o como depósitos en el citosol. Además, el hecho de no estar unidos por enlaces covalentes a otros componentes estructurales de la célula, facilita la purificación de estos polisacáridos desde la biomasa. En el caso de Euglena gracilis es posible obtener $\beta$-glucano con aproximadamente un $98 \%$ de pureza (Skov et al. 2012). Un factor importante a considerar es el alto valor nutricional de las microalgas, lo que incluye un alto contenido de ácidos grasos esenciales, proteínas, antioxidantes, vitaminas, entre otros nutrientes (Adarme-Vega et al. 2012). Este hecho permitiría entregar la biomasa completa como suplemento alimenticio o bien co-extraer otros productos de interés comercial, mejorando la rentabilidad de la producción de estos polisacáridos. Los

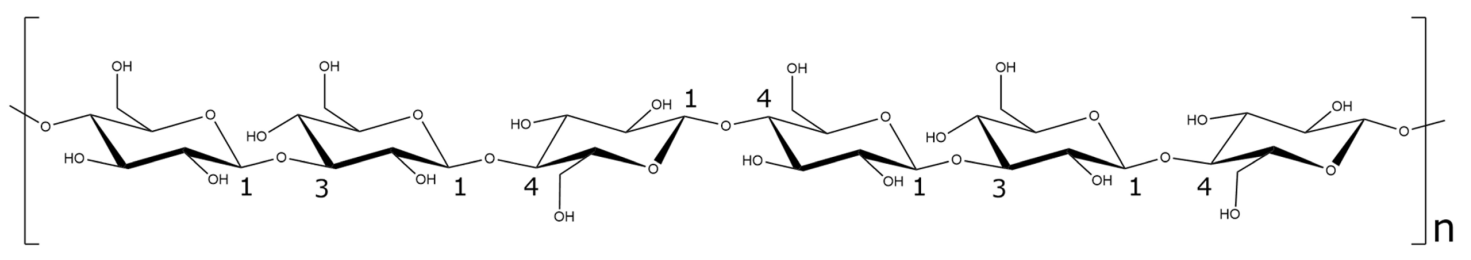

Figura 3. Estructura de 1,3;1,4- $\beta$-glucano lineal de enlaces mixtos de la avena y la cebada / Structure of lineal mixed-linkage 1,3;1,4$\beta$-glucan from oat and barley 
tipos de $\beta$-glucanos que se pueden encontrar en estos organismos varían según cada grupo o especie algal, siendo los principales la crisolaminarina y el paramilón (Usov \& Zelinsky 2013).

\subsection{Crisolaminarina}

La crisolaminarina está conformada por una cadena principal de unidades de D-glucosas unidas por enlaces $\beta-1,3$ con ramificaciones de residuos simples de glucosa unidas por enlaces $\beta-1,6$ (Fig. 4). Este polisacárido es muy similar a la laminarina presente en algas pardas (Ochrophyta, Phaeophyceae), con la diferencia que la crisolaminarina carece de manitol como residuo terminal en el extremo reductor (Painter 1983). Este polisacárido se ha encontrado presente como carbohidrato de reserva en microalgas de las divisiones Haptophyta y Ochrophyta. Esta última representada por las clases Chrysophyceae (extenso grupo de especies de fitoplancton y algas bentónicas) y la clase Bacillariophyceae (también conocidas como diatomeas) (van den Hoek et al. 1995). Se cree que otras clases dentro de la división Ochrophyta, como Dictyochophyceae, Raphidophyceae, Xanthophyceae y Eustigmatophyceae, la cual incluye al género Nannochloropsis, también almacenarían 1,3- $\beta$-glucanos similares a la crisolaminarina como carbohidratos de reserva (van den Hoek et al. 1995).

En el grupo de las diatomeas se han realizado la mayor cantidad de estudios sobre el metabolismo y la estructura de estos $\beta$-glucanos (Chiovitti et al. 2004, Myklestad \& Granum 2009), encontrándose información sobre las variables que influyen en su acumulación, degradación, enzimas asociadas a su síntesis, localización dentro de la célula, entre otras. Estos carbohidratos han sido localizados mediante el uso de tinción e inmunolocalización en vacuolas de varias especies como Pinnularia viridis, Phaeodactylum tricornutum y Thalassiosira pseudonana (Waterkeyn \& Bienfait 1987). Si bien no existen estudios sobre la actividad inmunoestimulante de la crisolaminarina, estudios en laminarinas han encontrado que éstas poseen la capacidad de modular la función inmune uniéndose a receptores específicos de macrófagos (Sletmoen $\&$ Stokke 2008). Se han reportado prometedoras actividades antibacterianas en cerdos (Lynch et al. 2010) e inmunoestimulantes en ratas (Rice et al. 2005). A su vez, se ha visto que la despolimerización parcial de estos compuestos puede generar oligosacáridos más activos (Miyanishi et al. 2003, Pang et al. 2005, Kim et al. 2006). Además, se ha determinado que las laminarinas y sus derivados son capaces de estimular las defensas contra patógenos en plantas (Kobayashi et al. 1995, Ménard et al. 2004) y podrían inhibir la infección del VIH (Katsuraya et al. 1994).

\subsection{Paramilón}

El paramilón es un $\beta$-glucano fibrilar lineal (Fig. 4) formado por cadenas de glucosa unidas por enlaces $\beta-1,3$, utilizado como carbohidrato de reserva en la divisón Euglenophyta (Kreger \& Meeuse 1952, Clarke \& Stone 1960), la cual está formada por cerca de 40 géneros y unas 1000 especies de organismos unicelulares en su mayoría de agua dulce. El microorganismo productor de esta molécula más estudiado corresponde a la especie Euglena gracilis, la cual produce el

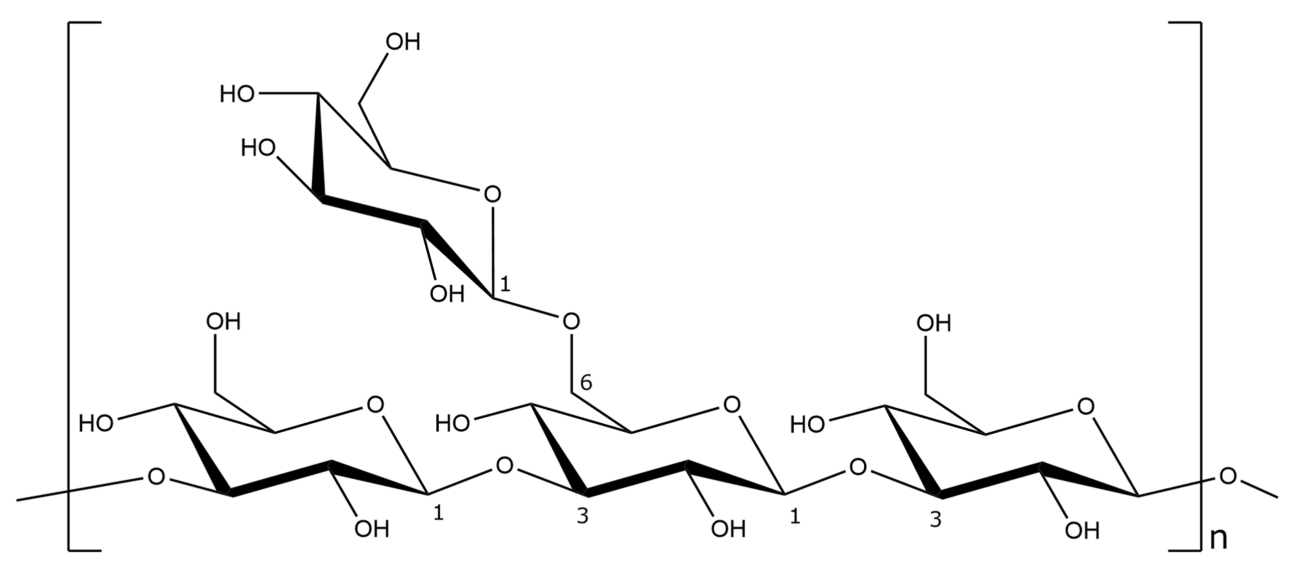

Figura 4. Estructura de 1,3;1,6- $\beta$-glucano ramificado como laminarina o crisolaminarina / Structure of side branched 1,3;1,6- $\beta$ glucan like laminarin or chrysolaminarin 
paramilón como un carbohidrato de reserva intracelular, que se acumula en forma de depósitos insolubles cristalinos. Siendo identificado en un comienzo, como un polisacárido isomérico del almidón (Gottlieb 1850), el paramilón ha atraído gran interés debido a sus propiedades inmunoestimulantes e inmunopotenciadoras (Kondo et al. 1992) y por su capacidad de ser fácilmente purificado desde gránulos insolubles, acumulados en grandes cantidades dentro de las células (entre un 40-90\%) (Barsanti et al. 2001). Se ha reportado que esta sustancia, al ser administrada en forma oral en distintos tipos de organismos, tendría múltiples efectos, como incremento de la resistencia al estrés en Artemia sp., incremento de la resistencia al parásito Ichthyophthirius multifiliis en trucha arcoíris, supresión de la lesión atópica de piel similar a dermatitis en ratones, además de otros efectos positivos, tanto en peces como mamíferos (Skov et al. 2012).

\subsection{Otros TIPOS DE $\boldsymbol{\beta}$-GLUCANOS PRESENTES EN ALGAS}

En dinoflagelados (Dinophyceae), las células están rodeadas por una compleja cobertura de celulosa denominada teca y en algunos casos tienen una delgada capa adicional que en especies como Peridinium cinctum estaría formada por $\beta$-glucanos lineales de enlaces $\beta-1,3$ y 1,4 (Nevo \& Sharon 1969). Análisis de metilación de los carbohidratos de reserva de 2 especies de Chlorarachnion (Chlorarachniophyceae), revelaron la presencia de un $\beta$-glucano lineal con enlaces $\beta-1,3$ de cadena larga. Mediante inmunolocalización se determinó que este polisacárido era almacenado en vacuolas que encapsulaban el pirenoides (McFadden et al. 1997). En algunas microalgas Haptophyta, como en el caso de Isochrysis galbana y Emiliania huxleyi, se han encontrado también otros tipos de $\beta$-glucanos de reserva diferentes a la crisolaminarina, conformados por una cadena principal de glucosas unidas por enlaces $\beta-1,6$ con ramificaciones unidas a ésta por enlaces $\beta$ 1,3 y que presentarían posibles efectos sobre el sistema inmune (Sadovskaya et al. 2014).

\subsection{GÉNERO NANNOCHLOROPSIS Y SUS ATRIBUTOS}

El género Nannochloropsis, perteneciente a la clase Eustigmatophyceae de la división Ochrophyta, comprendía 6 especies no flageladas de microorganismos fotosintéticos de células ovoides de un tamaño de 2-4 $\mu \mathrm{m}$ de diámetro, de las cuales 5 correspondían a especies marinas (Guiry \& Guiry 2016). Sin embargo, recientemente en el trabajo de Fawley et al. (2015) se encontró que dos de estas especies corresponderían a un nuevo género denominado Microchloropsis, el cual incluye a las especies Microchloropsis salina y Microchloropsis gaditana, junto con encontrar una nueva especie dentro del género
Nannochloropsis correspondiente a Nannochloropsis australis. Al igual que en otras Ochrophyta, cada célula presenta sólo un cloroplasto con 4 membranas, producto de un segundo evento endosimbiótico. El retículo endoplasmático se encuentra fusionado a la membrana exterior del cloroplasto formando el retículo endoplasmático asociado al cloroplasto, que es contínuo a la membrana externa de la envoltura nuclear. Sólo hay un tipo de clorofila presente en las especies de Nannochloropsis y Microchloropsis, la clorofila $a$, y el principal pigmento accesorio es la violaxantina (van den Hoek et al. 1995).

Muchas especies de Nannochloropsis presentan un enorme interés debido a su capacidad de acumular una gran cantidad de lípidos como el triacilglicerol (TAG) (utilizado para la síntesis de biocombustibles) y su exitoso cultivo a gran escala usando luz natural, tanto en piscinas abiertas como en sistemas cerrados. Esta producción ha sido lograda por compañías como Solix Biofuels, Aurora Algae, Seambiotic, Hairong Electric Company/ Seambiotic y Proviron (Radakovits et al. 2012). Sin embargo, la producción de biocombustibles a partir del cultivo de especies de este género aún no resulta rentable, debido a los altos costos de producción en comparación al combustible fósil (Chisti 2013). Por este motivo, la mayoría de los estudios se han centrado en el metabolismo de lípidos y la optimización de su producción con el fin de solucionar esta problemática. Dentro de los esfuerzos en investigación realizados, se encuentra la secuenciación de los genomas de varias especies y el desarrollo de técnicas de manipulación genética (Radakovits et al. 2012, Vieler et al. 2012).

Por otra parte, algunas especies de Nannochloropsis han sido utilizadas como alimento de rotíferos y peces en acuicultura, debido a su rápido crecimiento y alto contenido de ácidos grasos esenciales necesarios en la dieta de estos organismos (Apt \& Behrens 1999), como es el caso del ácido eicosapentanoico (EPA), cuyo contenido varía de un 24 a $28 \%$ del contenido total de lípidos dependiendo de la especie y condiciones de cultivo (Hu \& Gao 2003, Patil et al. 2007, Van Wagenen et al. 2012). A esto, se suma un alto contenido de pigmentos y antioxidantes, como clorofila $a, \beta$-caroteno, violaxantina y vaucheriaxantina (Macías-Sánchez et al. 2005), todos compuestos de alto valor agregado en el mercado. Estas especies son incapaces de sintetizar almidón (van den Hoek et al. 1995). Los resultados de la secuenciación de los genomas indica que poseen grupos de genes involucrados en la síntesis de 1,3- $\beta$-glucanos (Radakovits et al. 2012, Vieler et al. 2012, Corteggiani-Carpinelli et al. 2014, Wang et al. 2014), sugiriendo que el género Nannochloropsis (incluidas las especies correspondientes al nuevo género Microchloropsis) podría ser capaz de almacenar laminarina o crisolaminarina, al 
igual como ocurre en otras Ochrophyta. En el trabajo de Vieler et al. (2012), se realizaron preparaciones de residuos insolubles en alcohol a partir de biomasa liofilizada de Nannochloropsis oceanica CCMP1779, las cuales fueron digeridas mediante dos tratamientos enzimáticos, EGII (enzima específica para $\beta$ 1,4-glucanos) o laminarinasa (específica para $\beta$-1,3-glucanos). Se obtuvo que el tratamiento con EGII liberó el $85 \%$ de la glucosa contenida en los residuos insolubles en alcohol, mientras que el tratamiento con laminarinasa un $20 \%$ (ver Fig. 5). Sin embargo, en ese trabajo no se señala qué porcentaje de la biomasa generada y utilizada para el ensayo corresponde a 1,3$\beta$-glucanos. En la investigación de Jia et al. (2015), la cual será descrita en mayor detalle en párrafos posteriores, se sugiere que estos polisacáridos podrían corresponder entre un 5 a un $8 \%$ de la biomasa seca de Nannochloropsis oceanica IMET1. Respaldando los resultados de las secuenciaciones de los genomas y los experimentos anteriormente mencionados, Arnold et al. (2014) describieron la presencia de crisolaminarina en Nannochloropsis oculata y Diacronema lutheri a través de análisis de NMR-C ${ }^{13}$ (Carbon-13 Nuclear Magnetic Resonance) en células vivas, validando a nivel bioquímico la presencia de este polímero en Nannochloropsis y en Pavlova (Haptophyta). Esta crisolaminarina tendría estructura similar a la encontrada en otras especies, sin embargo nuevos estudios debieran validar su actividad inmunoestimulante y propiedades benéficas en animales y humanos. La presencia de este polímero sumaría valor agregado al cultivo de Nannochloropsis con fines comerciales.

\section{VARIAbles de CUltivo QUe afeCtan la PROdUCCIÓN DE 1,3- $\beta$-GLUCANOS}

En microalgas, factores ambientales como el tipo de luz e intensidad lumínica, temperatura, disponibilidad de nutrientes, pH y salinidad, han sido descritos como los más influyentes sobre la composición de las células en los cultivos (Richmond $\& \mathrm{Hu}$ 2013). Se han realizado diversas investigaciones que se refieren a la influencia de estos factores, con la finalidad de mejorar la producción de metabolitos de interés como antioxidantes, carotenoides, pigmentos, lípidos, carbohidratos, entre otros. En cuanto a la acumulación de moléculas de reserva como lípidos y carbohidratos, los factores descritos con mayor influencia son la intensidad lumínica y la disponibilidad de nutrientes como nitrógeno y carbono, este último ya sea inorgánico u orgánico.

\subsection{INTENSIDAD LUMÍNICA}

El aumento de la intensidad lumínica y la falta de nutrientes como nitrógeno y fosfato, conlleva a un aumento en el contenido celular de bioproductos fotosintéticos de reserva como lípidos

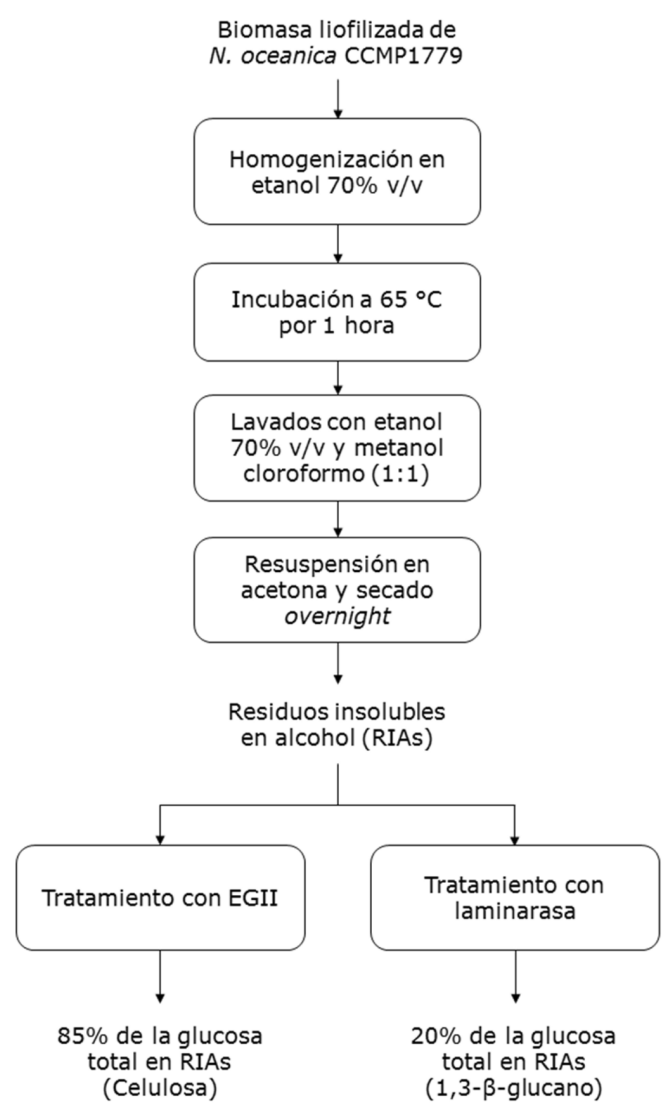

Figura 5. Esquema de la metodología y resultados del ensayo de digestión enzimática realizado por Vieler et al. (2012) en residuos insolubles en alcohol (RIAs) de Nannochloropsis oceanica CCM P1779 / Methodology and results diagram of the enzimatic digestion assay conduted by Vieler et al. (2012) on alcohol-insoluble residues (AIRs) from Nannochloropsis oceanica CCMP1779

(TAG) y carbohidratos (almidón y 1,3- $\beta$-glucanos), siendo este un mecanismo adaptativo de sobrevivencia frente a condiciones adversas (Harwood \& Guschina 2009). Se ha descrito en varias clases de microalgas que la intensidad lumínica es proporcional al contenido de lípidos totales, es decir, a mayor intensidad lumínica, mayor es el contenido de éstos. Sin embargo, el contenido de ácidos grasos poliinsaturados (PUFAs), lo que incluye EPA, es inversamente proporcional a la intensidad lumínica de los cultivos. Sukenik et al. (1987) demostraron que las células de Nannochloropsis presentaban altos niveles de EPA bajo condiciones de limitación lumínica, mientras que en condiciones de alta intensidad lumínica predominan las especies de ácidos grasos 16:0 y 16:1, los cuales están presentes principalmente como triacilglicerol formando cuerpos lipídicos en el citosol (Hu et al. 2008). Se ha determinado que un aumento de la intensidad lumínica, aumenta el contenido de 
polisacáridos a nivel celular en varias especies (Richmond \& Hu 2013). En Chlorella vulgaris, por ejemplo, un aumento de la intensidad lumínica de 215 a $330 \mu \mathrm{mol} \mathrm{m} \mathrm{m}^{-2} \mathrm{~s}^{-1}$ generó un incremento en el contenido de almidón desde un 8,5 a un $40 \%$ (Brányiková et al. 2011). En diatomeas, la crisolaminarina (1,3;1,6- $\beta$-glucano) es sintetizada durante el día y degradada durante la noche (Vårum \& Myklestad 1984, Granum et al. 2001). Bajo una alta intensidad lumínica y ausencia de nitrógeno en el medio, la crisolaminarina llega a formar cerca del $85 \%$ del carbono orgánico de la célula en Skeletonema costatum (Granum et al. 2001). Resultados similares se obtuvieron en Odontella obtusa, donde una intensidad lumínica de $300 \mu \mathrm{mol} \mathrm{m}^{-2} \mathrm{~s}^{-1}$ otorga un contenido en crisolaminarina de casi el doble en porcentaje de biomasa seca de este polisacárido en comparación a una intensidad lumínica de $100 \mu \mathrm{mol} \mathrm{m}^{-2} \mathrm{~s}^{-1}$ (Xia et al. 2014). A pesar que cambios en la intensidad lumínica generan resultados significativos a nivel productivo, este factor es casi imposible de controlar en cultivos a gran escala al aire libre (Millán-Oropeza et al. 2015). Además, se han reportado efectos de fotoinhibición, principalmente del fotosistema II, en sistemas de cultivo al aire libre debido a la excesiva intensidad lumínica proveniente a mediodia del sol, lo cual inhibe el crecimiento y productividad de biomasa (Murata et al. 2007).

\subsection{Disponibilidad DE NITRÓGENO EN EL MEDIO}

Otro factor de importancia es la disponibilidad de nutrientes en el medio, el cual es el factor más conveniente y documentado con la finalidad de ser controlado. Uno de los nutrientes más influyente sobre la composición celular es el nitrógeno y se ha descrito que al agotarse éste en el medio de cultivo de varias especies de microalgas, como Chaetoceros muelleri, Lobosphaera incisa, Ettlia oleoabundans y Chlamydomonas reinhardtii, se observan incrementos significativos en el contenido de lípidos a nivel celular, especialmente triacilglicerol, como también un aumento en el contenido de carbohidratos totales (Dong et al. 2013). Algunas especies son capaces de acumular entre un $40-63 \%$ de su peso seco en contenido de lípidos totales en medios con bajas concentraciones de nitrógeno (Illman et al. 2000). En cuanto a carbohidratos de reserva, en Chlorella vulgaris la ausencia de nitrógeno aumenta el contenido de almidón hasta un 55\% de su peso en biomasa seca (Brányiková et al. 2011). En diatomeas ocurre algo similar, donde la falta de nitrógeno conlleva a un aumento significativo en la acumulación de crisolaminarina, llegando a valores cercanos al 70-80\% del carbono orgánico total de las células en especies como Skeletonema costatum y Chaetoceros pseudocurvisetus (Vårum \& Myklestad 1984, Granum et al. 2001, Myklestad \& Granum 2009). Contrariamente, cuando el nitrógeno es abundante, la crisolaminarina es degradada para apoyar la síntesis proteica (Myklestad \& Granum 2009).
En el caso de Nannochloropsis, el nitrógeno es uno de los factores más estudiados con el fin de optimizar el contenido lipídico de las células, donde ha sido reportado que su agotamiento provoca un aumento significativo en el contenido de ácidos grasos saturados, como TAG (Dong et al. 2013), llegando a niveles de entre un 60-70\% de lípidos totales de su biomasa seca. En cuanto a carbohidratos, se cuenta con escasos estudios respecto de lo que ocurre a nivel celular. La mayoría de las investigaciones solo han cuantificado el contenido de carbohidratos totales en respuesta frente a algunas condiciones de cultivo. En el trabajo de Jia et al. (2015), el contenido de carbohidratos totales en Nannochloropsis oceanica aumentó de un 5,8 a un $17,9 \%$ de su biomasa seca durante los primeros 4 días luego del agotamiento abrupto del nitrógeno en el medio, para posteriormente aumentar a un $19,1 \%$ al día 14 . En este mismo trabajo, se evidenció que el contenido de 1,3- $\beta$ glucanos, expresado como glucosa polimérica y sugerida como laminarina por los autores, aumentó de un 1,63 a un 7,87\% al día 8 , luego del estrés por ausencia de nitrógeno, para finalmente decaer a un $6,28 \%$ al día 14 .

\subsection{Disponibilidad de carbono inORgánico}

Si bien la estrategia de limitación de nitrógeno logra aumentar significativamente el contenido de lípidos y carbohidratos de interés a nivel celular en las microalgas, ésta involucra también una disminución de la división celular, lo que conlleva una baja productividad de biomasa durante este proceso. A esto, se suma que, uno de los principales problemas del cultivo de microalgas con fines comerciales son las bajas concentraciones de biomasa obtenidas fotoautotróficamente, debido principalmente a un ineficiente uso de la energía lumínica del sol en los sistemas de cultivo actuales. Una de las estrategias propuestas para compensar esta problemática es la de suministrar carbono inorgánico adicional, ya sea en la forma de bicarbonato $\left(\mathrm{NaHCO}_{3}\right)$ o dióxido de carbono gaseoso $\left(\mathrm{CO}_{2}\right)$. Se ha observado que la adición de estos compuestos carbonados no solo promueve la producción de biomasa, sino que también la de lípidos y carbohidratos, junto con mejorar la asimilación del nitrógeno (Chiu et al. 2009, Lin et al. 2012). Así mismo, el crecimiento específico de las microalgas puede aumentar hasta tres veces al utilizar un suministro de $\mathrm{CO}_{2}$ de 2$5 \%$ en la aireación (Chiu et al. 2009). En Nannochloropsis, una concentración de $\mathrm{CO}_{2}$ de $2 \%$ en la aireación de los cultivos ha otorgado los mejores resultados en cuanto a productividad de biomasa y lípidos, mientras que sobre un 5\% se observa una inhibición del crecimiento (Chiu et al. 2009, Hanson et al. 2014, Yangüez et al. 2015). Hsueh et al. (2009) observaron en $N$. oculata una acumulación de carbohidratos totales de un $29 \%$ de su biomasa seca, al suministrar $\mathrm{CO}_{2}$ al $5 \%$ en la aireación, mientras que al utilizar un $8 \%$ de $\mathrm{CO}_{2}$ se obtuvo un 
$37 \%$ de carbohidratos totales. Esto sugiere que el contenido de carbohidratos, al igual que el de lípidos, se relaciona proporcionalmente con el suministro de $\mathrm{CO}_{2}$. No existen reportes en cuanto a la relación del contenido de 1,3- $\beta$-glucanos y el suministro de carbono inorgánico en estas especies, aunque el aumento de carbohidratos totales sugiere que podría deberse en parte al aumento de estos polisacáridos de reserva a nivel celular. Las emisiones de $\mathrm{CO}_{2}$ son unas de las principales causantes del efecto invernadero en el planeta. Este gas es producido como desecho tanto en procesos industriales, procesos de generación de energía (como termoeléctricas), fermentaciones de vino, cerveza, entre otros, y es liberado a la atmósfera siendo parte de los factores que generan hoy en día el calentamiento global (Hofmann et al. 2006). Estas emisiones podrían ser utilizadas para suministrar $\mathrm{CO}_{2}$ a cultivos de microalgas, como Nannochloropsis, con el fin de mejorar la productividad de lípidos de interés o 1,3- $\beta$-glucanos, disminuyendo así la emisión de éstas al medio ambiente, conllevando a un beneficio ambiental.

\subsection{Mixotrofía y heterotrofía}

Otra de las soluciones propuestas para mejorar la productividad de las microalgas, es el uso de condiciones de cultivo mixotróficas o heterotróficas, adicionando fuentes de carbono orgánicas al medio, donde el alga no solo se sustenta de la fotosíntesis para obtener su energía, sino que también de la degradación de moléculas orgánicas (Cerón-García et al. 2005). El uso de condiciones mixotróficas mejora la producción de biomasa, además de alterar la composición bioquímica de las células, aumentandola acumulación de compuestos de interés como lípidos y carbohidratos (Xu et al. 2004a, b; Cerón-García et al. 2005, 2013; Wan et al. 2011, Hanson et al. 2014).

Nannochloropsis es capaz de crecer de manera mixotrófica en presencia de fuentes de carbono orgánicas como glucosa y glicerol, mientras que la adición de etanol y acetato no presentan efectos positivos o incluso inhiben el crecimiento (Hu \& Gao 2003, Xu et al. 2004 a, b; Wan et al. 2011). Se ha descrito que el cultivo mixotrófico con glucosa, logra aumentar la producción de biomasa hasta en un $40 \%$, como también el contenido de lípidos y carbohidratos totales. Algunas de estas fuentes de carbono orgánicas son subproductos industriales, como es el caso del glicerol, que llega a representar el 10\% de los productos generados en la transesterificación de aceites vegetales o grasas animales dentro de la producción de biocombustibles (da Silva et al. 2009). El exceso de producción de glicerol puede convertirse en un gran problema al no poder ser liberado directamente al medio ambiente, requiriendo procesos complejos de eliminación y aumentando los costos de producción. Una solución es acoplar a este proceso productivo un cultivo de microalgas capaces de asimilar el glicerol residual generado, incorporando esta molécula a su metabolismo y convirtiéndola en biomasa u otras moléculas de interés comercial, como triacilglicerol o ácidos grasos omega 3 (da Silva et al. 2009). En Phaeodactylum tricornutum por ejemplo, se aumentó 13 veces la productividad de EPA al suministrar el medio de cultivo periódicamente con glicerol 0,1 M y con urea 0,1 M, obteniendo una productividad de 43,13 mg L ${ }^{-1}$. En Nannochloropsis oculata, se observó en la producción de biomasa un aumento de 2,5 veces, al utilizar una concentración de glicerol de $3 \mathrm{~g} \mathrm{~L}^{-1}$ al día 9 de cultivo en comparación al control y, un aumento de 3,6 y 2 veces en la productividad de biomasa y contenido de lípidos, respectivamente, al utilizar una concentración de $2 \mathrm{~g} \mathrm{~L}^{-1}$ de glicerol (Gupta et al. 2016). En general, los reportes del efecto de la mixotrofía o heterotrofía sobre el contenido de carbohidratos de reserva como el almidón o 1,3- $\beta$-glucanos son escasos. En Euglena gracilis, se ha reportado un incremento en la acumulación de paramilón tantoen condiciones de cultivo mixotróficas como heterotróficas (Briand \& Calvayrac 1980, Kiss et al. 1986).

\section{Biología molecular del Metabolismo de 1,3- $\beta$ - GLUCANOS}

La mayoría de los eventos moleculares que ocurren durante la biosíntesis de 1,3- $\beta$-glucanos en microalgas aún no están del todo claros y estudios al respecto son escasos. El organismo donde existe mayor conocimiento al respecto es la levadura de cerveza (Saccharomyces cerevisiae) y la síntesis de callosa en plantas (Brownfield et al. 2009). En microalgas los organismos con mayor información al respecto son Euglena gracilis y algunas diatomeas (Bulone 2009).

La biosíntesis de $\beta$-glucanos en general considera varias etapas (Fig. 6). En levaduras, ésta comienza con la síntesis de un iniciador de la polimerización o primer, el cual es una pequeña cadena de glucosas unidas por enlaces $\beta-1,3$. El primer es transferido a una $\beta$-glucano sintasa asociada a membrana, la cual cataliza la transferencia de unidades glucosídicas desde un azúcar donador activado a un aceptor (Bulone 2009). Este azúcar donador correspondería a la UDPglucosa, la cual es formada a partir de la glucosa-1-fosfato proveniente de la ruta de la glicólisis/gluconeogénesis y UTP mediante la acción de la enzima UDP-glucosa pirofosforilasa (Shematek et al. 1980, Shematek \& Cabib 1980). Lo mismo ha sido sugerido para Euglena gracilis y diatomeas (Goldemberg \& Marechal 1963, Marechal \& Goldemberg 1964, Roessler 1987). El mecanismo de síntesis de los primers no ha sido identificado hasta el momento y mucho menos si éstos son estrictamente necesarios en el proceso. Tampoco se sabe cómo la polimerización es detenida. Sin embargo, se cree que el mecanismo sería bastante similar a lo que ocurre con los 


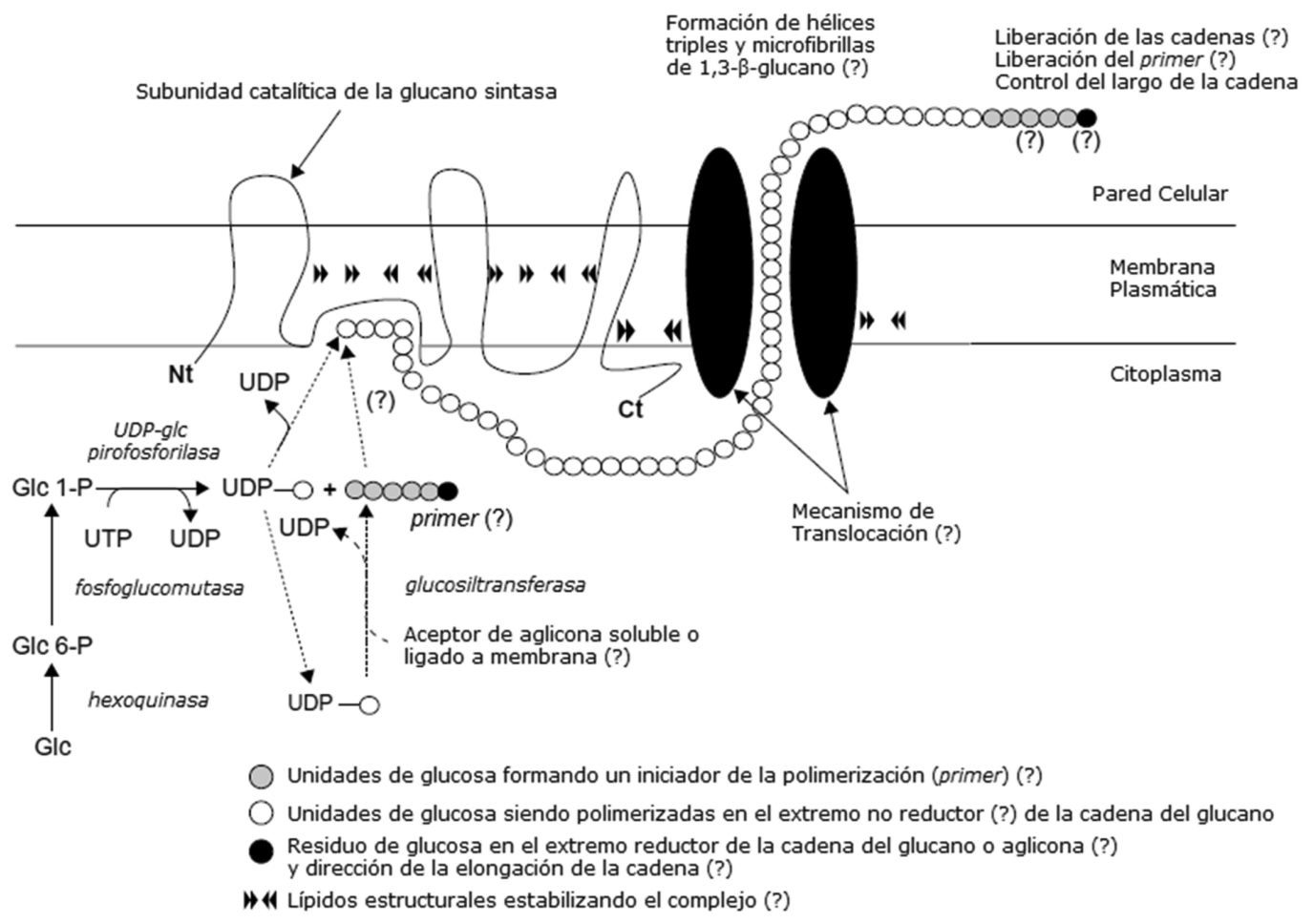

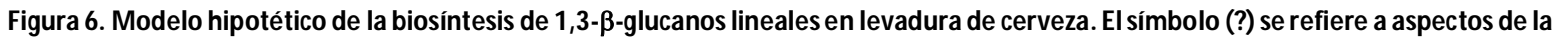
biosíntesis que permanecen sin ser aclarados; GIc: glucosa; UDP: Uridina difosfato; UTP: Uridina trifosfato; P: fosfato; Nt: N-terminal; Ct: C-terminal. Adaptado de Bulone (2009) / Hypothetical model for the biosynthesis of linear 1,3- $\beta$-glucans from yeast. (?) Refers to aspects that remain to be clarified; Glc: glucose; UDP: Uridine diphosphate; UTP: Uridine Triphosphate; P: phosphate; Nt: N-terminal; Ct: C-terminal. Adapted from Bulone (2009)

-1,4-glucanos, donde la síntesis de glicógeno o almidón requiere de un primer de glicoproteína y las ramificaciones se realizarían mediante el reordenamiento de la cadena del polisacárido a través de la acción de una transglicosilasa (Stoddart 1984).

Se sugiere que la 1,3- $\beta$-glucano sintasa cuenta con al menos dos subunidades: una subunidad catalítica ligada a membrana y una subunidad regulatoria de unión a GTP (Szaniszlo et al. 1985, Kang \& Cabib 1986, Mol et al. 1994). Estudios en Saccharomyces cerevisiae definieron que esta enzima corresponde a una proteína de 200 kDa y la determinación de la secuencia aminoacídica junto con el posterior clonamiento permitió la identificación de dos genes con una alta homología (88\% de identidad; Nogami \& Ohya 2009). Estos genes, FKS1 y $F K S 2$ codifican para proteínas de 1876 y 1895 aminoácidos, respectivamente, con 16 dominios transmembrana (Nogami \& Ohya 2009). La evidencia existente indica que estos genes codificarían para la subunidad catalítica de la 1,3- $\beta$-glucano sintasa, perteneciente a la familia glicosil transferasa 48 (GT48).
En el caso de la proteína FKS1 constaría de una estructura de 4 dominios funcionales: una cola citosólica $\mathrm{N}$-terminal $\sim 400$ aminoácidos involucrada en la actividad 1,3- $\beta$-glucano sintasa, una región de seis dominios transmembrana, formada por 300 aminoácidos requerida para la correcta localización de sitios de crecimiento polarizados, una región catalítica putativa de 600 aminoácidos y un C-terminal de 10 dominios transmembrana involucrada en la localización de la proteína a la superficie celular de $\sim 600$ aminoácidos (Dijkgraaf et al. 2002). Estos resultados permitieron la identificación posterior en plantas de una familia de genes denominada como Glucan Synthase-Like (GSL), también pertenecientes a la familia GT48, posiblemente involucrados en la síntesis de callosa (Brownfield et al.2009). En cuanto a la subunidad regulatoria de unión a GTP de la 1,3- $\beta$-glucano sintasa, la evidencia en levadura indica que corresponde a una GTPasa tipo Rho, familia de pequeñas proteínas $\mathrm{G}(20 \mathrm{kDa})$, relacionadas con señalización y codificadas por el gen RHOl (Drgonova et al. 1996, Qadota et al. 1996) la cual regularía la actividad de la 1,3- $\beta$-glucano sintasa mediante diversos mecanismos. Con respecto a la ruta 
de biosíntesis de las uniones $\beta-1,6$, la enzima que cataliza la síntesis de éstas no ha sido identificada (Nogami \& Ohya 2009). Se han encontrado los genes KRE6 y SKNI los cuales codifican para un par de proteínas homologas del aparato de Golgi muy similares a la familia 16 glicósido hidrolasas y cuya ausencia genera la disminución casi por completo de las ramificaciones $\beta-1,6$ en levadura. Sin embargo, la evidencia existente no es concluyente (Montijn et al. 1999).

En microalgas, las mayores limitaciones en dilucidar los mecanismos moleculares de biosíntesis de $\beta$-glucanos han sido la ausencia de los genomas secuenciados de estos organismos, junto con la dificultad de la preparación de transformantes estables y deleción de genes. Actualmente, se cuenta con la publicación de los genomas de los Oomycetes Phytophthora sojae, Phytophthora ramorum y Phytophthora infestans (Tyler et al. 2006), las diatomeas Thalassiosira pseudonana (Armbrust et al. 2004) y Phaeodactylum tricornutum (Kroth et al.2008) sumado a la publicación de los genomas de varias especies de Nannochloropsis (Wang et al. 2014). Análisis en dichos genomas han permitido la identificación de varios genes similares a los que codifican para las subunidades catalíticas putativas de la 1,3- $\beta$-glucano sintasa de plantas (denominadas como callosa sintasas), levaduras y hongos. Otros genes importantes involucrados en las rutas metabólicas de 1,3- $\beta$ glucanos también han sido identificados. Tal es el caso de la enzima UDP-glucosa pirofosforilasa, endo y exo-1,3- $\beta$ glucanasas y algunos similares al gen KRE6 y $S K N 1$ mencionados anteriormente en levadura como involucrados en generar las ramificaciones $\beta-1,6$ (Armbrust et al. 2004, Tyler et al. 2006, Kroth et al. 2008, Wang et al. 2014). Curiosamente, en el oomycete $P$. infestans uno de estos genes similares a KRE6 se encuentra fusionado a uno de los genes que codifican para una 1,3- $\beta$-glucano sintasa (Tyler et al. 2006). Finalmente cabe señalar, que la información sobre la regulación de todos estos genes involucrados en el metabolismo de 1,3$\beta$-glucanos es escasa. Los resultados de los transcriptomas en condición de estrés por ausencia de nitrógeno en el medio de Microchloropsis gaditana, Nannochloropsis oceanica y Nannochloropsis oculata reveló que tanto el gen de la 1,3- $\beta$ glucano sintasa y los de la UDP-glucosa pirofosforilasa son sobre expresados bajo estas condiciones, lo que se coindice con el aumento de 1,3- $\beta$-glucano a nivel celular observado por Jia et al. (2015). También se reportó el aumento de los genes involucrados en su degradación, como endo y exo-1,3$\beta$-glucanasas, lo que sugiere que estos polisacáridos serían una reserva de carbono temprana, siendo el TAG la reserva de carbono a largo plazo preferida por estas especies. En el trabajo de Jia et al. (2015) se presenta el análisis mediante qRT-PCR ('quantitative real-time reverse transcription-PCR', por sus siglas en inglés) de genes del metabolismo 1,3- $\beta$-glucano, en el cual se reportó que el estrés por ausencia de nitrógeno provocó un aumento en los niveles de transcrito de genes putativos para las enzimas fosfoglucomutasa (de 0,05 a 0,5 aproximadamente) y UDP-glucosa pirofosforilasa (de 0,035 a 0,6 aproximadamente) durante los primeros 3 días. Por otra parte, un leve aumento en los niveles de transcrito de $1,3-\beta$ glucano sintasa (de 0,4 a 1) se registró durante este mismo periodo junto con un marcado aumento al día 8 de tratamiento (a valores de $\sim 2,0$ ). Otro gen, al cual los autores denominaron $\beta$-1,3-glucosil transferasa, presentó un marcado aumento en sus niveles de transcrito al día 1 y 8 del tratamiento (de $\sim 0,2$ a 0,6). En este contexto, la disminución de los niveles de expresión de estos genes, respaldaría la hipótesis que los 1,3- $\beta$-glucanos serían una reserva de carbono temprana en la célula algal.

\section{Discusión}

Una de las principales metas que se propone a través del cultivo de microalgas, es el poder lograr la producción sustentable y económicamente rentable de la biomasa. En una primera etapa, se evaluó la utilización de esta biomasa en la producción de biocombustibles capaces de remplazar los combustibles fósiles. A la fecha, no se ha podido lograr la producción a gran escala de combustibles a partir de microalgas, debido a los altos costos de producción asociados al cultivo de estos organismos y al bajo valor agregado de los combustibles generados, lo que ha hecho imposible su rentabilidad económica (Chisti 2013). Por otro lado, la producción de compuestos de alto valor agregado, como los nutracéuticos, está ganando cada vez más terreno con productos como la astaxantina, luteína, ácidos grasos omega 3 , entre otros, los cuales presentan una demanda creciente y alto valor en el mercado (Bishop \& Zubeck 2012). Nannochloropsis es uno de los géneros que ha sido considerado como candidato para la producción de biodiesel (Radakovits et al. 2012). En el trabajo de Jia et al. (2015), se obtuvo que Nannochloropsis oceanica IMET1 acumula entre un 5-8\% de 1,3- $\beta$-glucano. Los autores plantean este tipo de carbohidratos como un subproducto no deseado cuyo carbono utilizado en su síntesis podría ser redireccionado mediante ingeniería metabólica con el fin de aumentar el contenido de TAG para la síntesis de biodiesel. Sin embargo, estos carbohidratos, debido a sus propiedades benéficas sobre la salud humana y animal, podrían ser un valioso subproducto de alto valor agregado, ayudando a solventar los altos costos productivos en estas especies. Para esto, son requeridos nuevos estudios enfocados en las condiciones que influyen en su acumulación junto con la caracterización molecular del polisacárido y la validación de los efectos inmunomoduladores u otras propiedades, así como también, la determinación del 
remanente de estas moléculas luego de realizados los procesos de extracción de lípidos, tal como se hace con otros componentes celulares de interés como proteínas.

Tanto diatomeas como Euglena gracilis cuentan con abundantes estudios sobre 1,3- $\beta$-glucanos y sus propiedades (Bulone 2009), pero su cultivo presenta mayores dificultades que por ej. las especies de Nannochloropsis las que cuentan con cultivo y producción estables a gran escala (Radakovits et al. 2012). Además, 6 de las 7 especies de Nannochloropsis y Microchloropsis corresponden a microorganismos marinos (Guiry \& Guiry 2016), lo que permite la utilización de agua de mar, recurso prácticamente ilimitado, sin competir con la cada vez más escasa agua dulce, lo cual no es posible en el caso de Euglena.

\section{Conclusión}

En base a los antecedentes recopilados, se puede afirmar que el género Nannochloropsis (incluyendo las especies descritas recientemente como Microchloropsis) presenta un gran potencial para la producción sustentable de nutracéuticos como los 1,3- $\beta$-glucanos. No obstante, se requieren mayores estudios con respecto a estas moléculas tales como caracterización, métodos eficientes de extracción y análisis de las rutas metabólicas involucradas en su producción.

\section{Agradecimientos}

Este trabajo se desarrolló gracias al financiamiento del Proyecto FIA PYT 2016-0339 y FONDECYT 11090234 a NE. Se agradece a los tres revisores anónimos designados por la Revista de Biología Marina y Oceanografía que contribuyeron a la mejora de este manuscrito.

\section{LITERATURA CITADA}

Adarme-Vega TC, DKY Lim, M Timmins, F Vernen, Y Li \& PM Schenk 2012. Microalgal biofactories: a promising approach towards sustainable omega-3 fatty acid production. Microbial Cell Factories 11(1): 96. <doi: 10.1186/1475-285911-96>

Apt KE \& PW Behrens. 1999. Commercial developments in microalgal biotechnology. Journal of Phycology 35: 215-226.

Arena MP, G Caggianiello, D Fiocco, P Russo, M Torelli, G Spano \& V Capozzi. 2014. Barley $\beta$-glucans-containing food enhances probiotic performances of beneficial bacteria. International Journal of Molecular Science 15(2): 3025-3039.

Armbrust EV, JA Berges, C Bowler, BR Green, D Martinez, NH Putnam, SG Zhou, AE Allen, KE Apt, M Bechner, MA Brzezinski, BK Chaal, A Chiovitti, AK Davis, MS Demarest, JC Detter, T Glavina, D Goodstein, MZ Hadi, U Hellsten, M Hildebrand, BD
Jenkins, J Jurka, VV Kapitonov, N Kroger, WWY Lau, TW Lane, FW Larimer, JC Lippmeier, S Lucas, M Medina, A Montsant, M Obornik, MS Parker, B Palenik, GJ Pazour, PM Richardson, TA Rynearson, MA Saito, DC Schwartz, K Thamatrakoln, K Valentin, A Vardi, FP Wilkerson \& DS Rokhsar. 2004. The genome of the diatom Thalassiosira pseudonana: Ecology, evolution, and metabolism. Science 306(5693): 79-86.

Arnold AA, B Genard, F Zito, R Tremblay, DE Warschawski \& I Marcotte. 2014. Identification of lipid and saccharide constituents of whole microalgal cells by ${ }^{13} \mathrm{C}$ solid-state NMR. Biochimica et Biophysica Acta - Biomembranes 1848(1-B): 369-377.

Azua-Bustos A \& C González-Silva. 2014. Biotechnological applications derived from microorganisms of the Atacama Desert. BioMed Research International 2014, Article ID 909312. <http://dx.doi.org/10.1155/2014/909312>

Barsanti L, R Vismara, V Passarelli \& P Gualtieri. 2001. Paramylon ( $\beta-1,3$-glucan) content in wild type and WZSL mutant of Euglena gracilis. Effects of growth conditions. Journal of Applied Phycology 13: 59-65.

Bishop WM \& HM Zubeck. 2012. Evaluation of microalgae for use as nutraceuticals and nutritional supplements. Journal of Nutrition and Food Science 2:147. <doi:10.4172/21559600.1000147>.

Bohn JA \& JN BeMiller. 1995. ( $1 \rightarrow 3)-\beta$-D-Glucans as biological response modifiers: a review of structure-functional activity relationships. Carbohydrate Polymers 28(1): 3-14.

Bold HC \& MJ Wynne. 1985. Introduction to the algae structure and reproduction, 270 pp. Prentice Hall, Englewood Cliffs.

Borowitzka MA. 1999. Commercial production of microalgae: ponds, tanks, and fermenters. Progress in Industrial Microbiology 35: 313-321.

Brányiková I, B Maršálková, J Doucha, T Brányik, K Bišová, V Zachleder \& M Vítová. 2011. Microalgae-novel highly efficient starch producers. Biotechnology and Bioengineering 108: 766-776.

Briand J \& R Calvayrac. 1980. Paramylon synthesis in heterotrophic and photoheterotrophic Euglena (Euglenophyceae). Journal of Phycology 16: 234-239.

Brown GD \& DL Williams. 2009. (1,3)- $\beta$-Glucans in innate immunity: Mammalian systems. In: Bacic A, GB Fincher \& BA Stone (eds). Chemistry, biochemistry, and biology of $1 \rightarrow 3-\beta$-glucans and related polysaccharides, pp. 587-627. Elsevier, Burlington.

Brownfield L, M Doblin, GB Fincher \& A Bacic. 2009. Biochemical and molecular properties of biosynthetic enzymes for (1,3)- $\beta$-Glucans in Embryophytes, Chlorophytes and Rhodophytes. In: Bacic A, GB Fincher \& BA Stone (eds). Chemistry, biochemistry, and biology of $1 \rightarrow 3-\beta-$ Glucans and related polysaccharides, pp. 283-326. Elsevier, Burlington. 
Bulone V. 2009. Biosynthetic enzymes for $(1,3)-\beta$-glucans and $(1,3 ; 1,6)$ - $\beta$-glucans in protozoans and chromistans: Biochemical characterization and molecular biology. In: Bacic A, GB Fincher \& BA Stone (eds). Chemistry, biochemistry, and biology of $1 \rightarrow 3$ - $\beta$-glucans and related polysaccharides, pp. 233-258. Elsevier, Burlington.

Cerón-García MC, A Sánchez-Mirón, JM FernándezSevilla, E Molina-Grima \& F García-Camacho. 2005. Mixotrophic growth of the microalga Phaeodactylum tricornutum: influence of different nitrogen and organic carbon sources on productivity and biomass composition. Process Biochemistry 40: 297-305.

Cerón-García MC, JM Fernández-Sevilla, A SánchezMirón, F García-Camacho, A Contreras-Gómez \& E Molina-Grima. 2013. Mixotrophic growth of Phaeodactylum tricornutum on fructose and glycerol in fedbatch and semi-continuous modes. Bioresources Technology 147:569-576.

Chihara G, J Hamuro, Y Maeda, Y Arai \& F Fukuoka. 1970. Antitumour polysaccharide derived chemically from natural glucan (Pachyman). Nature 225: 943-944.

Chiovitti A, P Molino, SA Crawford, R Teng, T Spurck \& R Wetherbee. 2004. The glucans extracted with warm water from diatoms are mainly derived from intracellular chrysolaminaran and not extracellular polysaccharides. European Journal of Phycology 39: 117-128.

Chisti Y. 2013. Constraints to commercialization of algal fuels. Journal of Biotechnology 167: 201-214.

Chiu SY, CY Kao, MT Tsai, SC Ong, CH Chen \& CS Lin. 2009. Lipid accumulation and $\mathrm{CO}_{2}$ utilization of Nannochloropsis oculata in response to $\mathrm{CO}_{2}$ aeration. Bioresources Technology 100(2): 833-838.

Clarke AE \& BA Stone. 1960. Structure of the paramylon from Euglena gracilis. Biochimica et Biophysica Acta 44: 161-163.

Corteggiani-Carpinelli E, A Telatin, N Vitulo, C Forcato, M D'Angelo, R Schiavon, A Vezzi, GM Giacometti, T Morosinotto \& G Valle. 2014. Chromosome scale genome assembly and transcriptome profiling of Nannochloropsis gaditana in nitrogen depletion. Molecular Plant 7: 323-335.

da Silva GP, M Mack \& J Contiero. 2009. Glycerol: A promising and abundant carbon source for industrial microbiology. Biotechnology Advances 27:30-39.

Dijkgraaf GJ, M Abe, Y Ohya \& H Bussey. 2002. Mutations in Fks1p affect the cell wall content of $\beta-1,3-$ and $\beta-1,6-$ glucan in Saccharomyces cerevisiae. Yeast 19: 671-690.

Dong HP, E Williams, DZ Wang, ZX Xie, RC Hsia, A Jenck, R Halden, J Li, F Chen \& AR Place. 2013. Responses of Nannochloropsis oceanica IMET1 to Long-Term Nitrogen starvation and recovery. Plant Physiology 162: 11101126.
Drgonova J, T Drgon, K Tanaka, R Kollar, GC Chen, RA Ford, CS Chan, Y Takai \& E Cabib. 1996. Rholp, a yeast protein at the interface between cell polarization and morphogenesis. Science 272(5259): 277-279.

Evans SG, D Morrison, Y Kaneko \& I Havlik. 1998. The effect of curdlan sulfate on development in vitro of Plasmodium falciparum. Transactions of the Royal Society of Tropical Medicine and Hygiene 92: 87-89.

Fawley MW, I Jameson \& KP Fawley. 2015. The phylogeny of the genus Nannochloropsis (Monodopsidaceae, Eustigmatophyceae), with descriptions of $N$. australis sp. nov. and Microchloropsis gen. nov. Phycologia 54: 545-552.

Goldemberg SH \& LR Marechal. 1963. Biosynthesis of paramylon in Euglena gracilis. Biochimica et Biophysica Acta 71: 743-744.

Gottlieb J. 1850. Über eine neue, mit Stärkmehl isomere Substanz. Annalen der Chemie und Pharmacie 75: 51-61.

Granum E, S Kirkvold \& SM Myklestad. 2001. Cellular and extracellular production of carbohydrates and amino acids by the marine diatom Skeletonema costatum: diel variations and effects of $\mathrm{N}$ depletion. Marine Ecology Progress Series 242: 83-94.

Guiry MD \& GM Guiry. 2016. AlgaeBase. World-wide electronic publication, National University of Ireland, Galway. $<$ http://www.algaebase.org>

Gupta PL, HJ Choi \& S Lee. 2016. Enhanced nutrient removal from municipal wastewater assisted by mixotrophic microalgal cultivation using glycerol. Environmental Science and Pollution Research International 23: 10114-10123.

Hanson DT, AM Collins, HD Jones, J Roesgen, S LopezNieves \& JA Timlin. 2014. On-line stable isotope gas exchange reveals an inducible but leaky carbon concentrating mechanism in Nannochloropsis salina. Photosynthesis Research 121: 311-322.

Harwood JL \& IA Guschina. 2009. The versatility of algae and their lipid metabolism. Biochimie 91: 679-684.

Hofmann DJ, JH Butler, EJ Dlugokencky, JW Elkins, K Masarie, SA Montzka \& P Tans. 2006. The role of carbon dioxide in climate forcing from 1979 to 2004: Introduction of the Annual Greenhouse Gas Index. Tellus Series B 58: 614619.

Hsueh HT, WJ Li, HH Chen \& H Chu. 2009. Carbon biofixation by photosynthesis of Thermosynechococcus sp. CL1 and Nannochloropsis oculta. Journal of Photochemistry and Photobiology B: Biology 95: 33-39.

Hu H \& K Gao. 2003. Optimization of growth and fatty acid composition of a unicellular marine picoplankton, Nannochloropsis sp., with enriched carbon sources. Biotechnology Letters 25: 421-425.

Hu Q, M Sommerfeld, E Jarvis, M Ghirardi, M Posewitz, M Seibert \& A Darzins. 2008. Microalgal triacylglycerols as feedstocks for biofuel production: perspectives and advances. Plant Journal 54: 621-639. 
Illman AM, AH Scragg \& SW Shales. 2000. Increase in Chlorella strains calorific values when grown in low nitrogen medium. Enzyme and Microbial Technology 27: 631-635.

Jagodzinski PP, R Wiaderkiewicz, G Kurzawski, M Kloczewiak, H Nakashima, E Hyjek, N Yamamoto, T Uryu, Y Kaneko, MR Posner \& D Kozbor. 1994. Mechanism of the inhibitory effect of curdlan sulfate on HIV1 infection in vitro. Virology 202: 735-745.

Jia J, D Han, HG Gerken, Y Li, M Sommerfeld, Q Hu \& J Xua. 2015. Molecular mechanisms for photosynthetic carbon partitioning into storage neutral lipids in Nannochloropsis oceanica under nitrogen-depletion conditions. Algal Research 7: 66-77.

John DM. 1994. Biodiversity and conservation: an algal perspective. The Phycologist 38: 3-15.

Kalra EK. 2003. Nutraceutical -definition and introduction. AAPS PharmSci 5(3): 27-28.

Kang MS \& E Cabib. 1986. Regulation of fungal cell wall growth: a guanine nucleotide-binding, proteinaceous component required for activity of $(1 \rightarrow 3)-\beta$-D-glucan synthase. Proceedings of the National Academy of Sciences of the United States of America 83: 5808-5812.

Kapteyn JC, H Van Den Ende \& FM Klis. 1999. The contribution of cell wall proteins to the organization of the yeast cell wall. Biochimica et Biophysica Acta 1426: 373383.

Katsuraya K, N Ikushima, N Takahashi, T Shoji, H Nakashima, N Yamamoto, T Yoshida \& T Urui. 1994. Synthesis of sulfated alkyl malto- and laminaraoligosaccharides with potent inhibitory effects on AIDS virus infection. Carbohydrate Research 260: 51-61.

Kim, JK, S Kottuparambil, SH Moh, TK Lee, YJ Kim, JS Rhee, EM Choi, BH Kim, YJ Yu, C Yarish \& T Han. 2015. Potential applications of nuisance microalgae blooms. Journal of Applied Phycology 27: 1223-1234.

Kim KH, YW Kim, HB Kim, BJ Lee \& DS Lee. 2006. Anti-apoptotic activity of laminarin polysaccharides and their enzymatically hydrolyzed oligosaccharides from Laminaria japonica. Biotechnology Letters 28: 439-446.

Kim MK, KE Ryua, WA Choi, YH Rheeb \& IY Lee. 2003. Enhanced production of $(1 \rightarrow 3)-\beta$-D-Glucan by a mutant strain of Agrobacterium species. Biochemical Engineering Journal 16: 163-168.

Kiss JZ, AC Vasconcelos \& RE Triemer. 1986. Paramylon synthesis and chloroplast structure associated with nutrient levels in Euglena (Euglenophyceae). Journal of Phycology 22:327-333.

Kobayashi A, A Tai \& K Kawazu. 1995. Structural elucidation of an elicitor-active oligosaccharide, $\mathrm{LN}-3$, prepared from algal laminaran. Journal of Carbohydrate Chemistry 14: 819832.

Kondo Y, A Kato, H Hojo, S Nozoe, M Takeuchi \& K Ochi. 1992. Cytokine-related immunopotentiating activities of paramylon, a $\beta-(1 \rightarrow 3)-\mathrm{D}-G l u c a n$ from Euglena gracilis. Journal of Pharmacobiodynamics 15: 617-621.

Kreger DR \& NJD Meeuse. 1952. X-ray of Euglenaparamylon, of the acid-insoluble glucan of yeast cell walls and of laminarin. Biochimica et Biophysica Acta 9: 699-700.

Kroth PG, A Chiovitti, A Gruber, V Martin-Jezequel, T Mock, MS Parker, MS Stanley, A Kaplan, L Caron, T Weber, U Maheswari, EV Armbrust \& C Bowler. 2008. A model for carbohydrate metabolism in the diatom Phaeodactylum tricornutum deduced from comparative whole genome analysis. PLoS ONE 3: e1426 <doi: 10.1371/ journal.pone.0001426>

Lee IY, WT Seo, GJ Kim, MK Kim, CS Park \& YH Park. 1997. Production of curdlan using sucrose and sugar cane molasses by two-step fed-batch cultivation of Agrobacterium species. Journal of Industrial Microbiology and Biotechnology 18:255-259.

Lin N, Y Li, L Tang, J Shi \& Y Chen. 2013. In vivo effect of oat cereal $\beta$-glucan on metabolic indexes and satiety-related hormones in diet-induced obesity C57-B1 mice. Molecular Nutrition Food Research 57: 1291-1294.

Lin Q, N Gu, G Li, J Lin, L Huang \& L Tan. 2012. Effects of inorganic carbon concentration on carbon formation, nitrate utilization, biomass and oil accumulation of Nannochloropsis oculata CS 179. Bioresource Technology 111:353-359.

Lynch MB, T Sweeney, JJ Callan, JT O'Sullivan \& JV O'Doherty. 2010. The effect of dietary Laminaria-derived laminarin and fucoidan on nutrient digestibility, nitrogen utilisation, intestinal microflora and volatile fatty acid concentration in pigs. Journal of the Science of Food and Agriculture 90: 430-437.

Macías-Sánchez MD, C Mantell, M Rodríguez, E Martínez de la Ossa, LM Lubián \& O Montero. 2005. Supercritical fluid extraction of carotenoids and chlorophyll a from Nannochloropsis gaditana. Journal of Food Engineering 66: 245-251.

Maehara Y, S Tsujitani, H Saeki, E Oki, K Yoshinaga, Y Emi, M Morita, S Kohnoe, Y Kakeji, T Yano \& H Baba. 2012. Biological mechanism and clinical effect of proteinbound polysaccharide K (KRESTIN®): review of development and future perspectives. Surgery Today 42: 828.

Mansour A, A Daba, N Baddour, M El-Saadani \& E Aleem. 2012. Schizophyllan inhibits the development of mammary and hepatic carcinomas induced by 7,12 dimethylbenz $(\alpha)$ anthracene and decreases cell proliferation: comparison with tamoxifen. Journal of Cancer Research and Clinical Oncology 138: 1579-1596.

Marechal LR \& SH Goldemberg. 1964. Uridine diphosphate glucose- $\beta$ - $(1,3)$-glucan $\beta$-3-glucosyltransferase from Euglena gracilis. Journal of Biological Chemistry 239: 3163 3167.

McFadden GI, PR Gilson \& IM Sims. 1997. Preliminary characterization of carbohydrate stores from 
chlorarachniophytes (Division: Chlorarachniophyta). Phycological Research 45: 145-151.

McFarlane HE,A Döring \& S Persson. 2014. The cell biology of cellulose synthesis. Annual Review of Plant Biology 65: 69-94

Ménard R, S Alban, P De Ruffray, F Jamois, G Franz, B Frigit, JC Yvin \& S Kauffmann. 2004. $\beta-1,3$ Glucan sulfate, but not $\beta-1,3$ glucan, induces the salicylic acid signaling pathway in tobacco and Arabidopsis. Plant Cell 16: 3020-3032.

Metzler-Zebeli BU \& Q Zebeli. 2013. Cereal $\beta$-glucan alters nutrient digestibility and microbial activity in the intestinal tract of pigs, and lower manure ammonia emission: A metaanalysis. Journal of Animal Science 91: 3188-3199.

Mikio K, O Yoshiro, O Hirotomo, K Yoshikazu, I Hiroshi, M Hisashi \& K Takeshi. 1995. Water soluble $\beta$-(1,3)Glucan derivative and antiviral agent containing the derivative. Japan Patent 07228601.

Millán-Oropeza A, LG Torres-Bustillos \& L FernándezLinares. 2015. Simultaneous effect of nitrate $\left(\mathrm{NO}_{3}-\right)$ concentration, carbon dioxide $\left(\mathrm{CO}_{2}\right)$ supply and nitrogen limitation on biomass, lipids, carbohydrates and proteins accumulation in Nannochloropsis oculata. Biofuel Research Journal 2(1): 215-221.

Miyanishi N, Y Iwamoto, E Watanabe \& T Oda. 2003. Induction of TNF- $\beta$ production from human peripheral blood monocytes with $\beta$-1,3-glucan oligomer prepared from laminarin with $\beta$-1,3-glucanase from Bacillus clausii NM1. Journal of Bioscience and Bioengineering 95: 192-195.

Mol PC, HM Park, JT Mullins \& E Cabib. 1994. A GTPbinding protein regulates the activity of $(1 \rightarrow 3)-\beta$-Glucan synthase, an enzyme directly involved in yeast cell wall morphogenesis. Journal of Biological Chemistry 269: 3126731274.

Montijn R, E Vink, W Müller, A Verkleij, H Van Den Ende, B Henrissat \& F Klis. 1999. Localization of synthesis of $\beta$-1,6-glucan in Saccharomyces cerevisiae. Journal of Bacteriology 181: 7414-7420.

Murata N, S Takahashi, Y Nishiyama \& SI Allakhverdiev. 2007. Photoinhibition of photosystem II under environmental stress. Biochimica et Biophysica Acta - Bioenergetics. 1767(6): 414-421.

Myklestad SM \& E Granum. 2009. Biology of (1,3)- $\beta$-glucans and related glucans in protozoans and chromistans. In: Bacic A, GB Fincher \& BA Stone (eds). Chemistry, biochemistry, and biology of $1 \rightarrow 3-\beta$-Glucans and related polysaccharides, pp. 353-385. Elsevier, Burlington.

Nakazato H, A Koike, S Saji, N Ogawa, J Sakamoto, H Nakazato, A Koike, S Saji, N Ogawa \& J Sakamoto. 1994. Efficacy of immunochemotherapy as adjuvant treatment after curative resection of gastric cancer. The Lancet 343: 1122-1126.
Nevo Z \& N Sharon. 1969. The cell wall of Peridinium westii, a non-cellulosic glucan. Biochimica et Biophysica Acta 173: 161-175.

Nogami S \& Y Ohya. 2009. Biosynthetic enzymes for (1-3)- $\beta$ glucans, (1-3;1-6)- $\beta$-glucans from yeasts: Biochemical properties and molecular biology. In: Bacic A, GB Fincher \& BA Stone (eds). Chemistry, biochemistry, and biology of $1 \rightarrow 3$ $\beta$-Glucans and related polysaccharides, pp. 259-282. Elsevier, Burlington.

Novak M \& V Vetvicka. 2009. Glucans as biological response modifiers. Endocrine, Metabolic \& Immune Disorders - Drug Targets 9: 67-75.

Onderdonk AB, RL Cisneros, P Hinkson \& G Ostroff. 1992. Anti-infective effect of poly- $\beta$ 1-6-glucotriosyl- $\beta$ 1-3glucopyranose glucan in vivo. Infection and Immunity 60 : 1642-1647.

Painter TJ. 1983. Algal polysaccharides. In: Aspinall GO (ed). The polysaccharids 2: 195-285. Academic Press, Oxford.

Pang Z, K Otaka, T Maoka, K Hidaka, S Ishijima, M Oda \& M Ohnishi. 2005. Structure of $\beta$-glucan oligomer from laminarin and its effect on human monocytes to inhibit the proliferation of U937 cells. Bioscience, Biotechnology, and Biochemistry 69: 553-558.

Patil V, T Källqvist, E Olsen, G Vogt \& HR Gislerød. 2007. Fatty acid composition of 12 microalgae for possible use in aquaculture feed. Aquaculture International 15: 1-9.

Qadota H, CP Python, SB Inoue, M Arisawa, Y Anraku, Y Zheng, T Watanabe, DE Levin \& Y Ohya. 1996. Identification of yeast Rho1p GTPase as a regulatory subunit of 1,3- $\beta$-Glucan synthase. Science 272: 279-281.

Radakovits R, RE Jinkerson, SI Fuerstenberg, H Tae, RE Settlage, JL Boore \& MC Posewitz. 2012. Draft genome sequence and genetic transformation of the oleaginous alga Nannochloropis gaditana. Nature Communications 3: 686. < doi:10.1038/ncomms1688>

Rice PJ, EL Adams, T Ozment-Skelton, AJ Gonzalez, MP Goldman, BE Lockhart, LA Barker, KF Breuel, WK Deponti, JH Kalbfleisch, HE Ensley, GD Brown, S Gordon \& DL Williams. 2005. Oral delivery and gastrointestinal absorption of soluble glucans stimulate increased resistance to infectious challenge. Journal of Pharmacology and Experimental Therapeutics 314: 10791086.

Richmond A. 2000. Microalgal biotechnology at the turn of the millennium: A personal view. Journal of Applied Phycology 12:441-451.

Richmond A \& Q Hu. 2013. Handbook of microalgal culture: Applied phycology and biotechnology, 736 pp. WileyBlackwell, Oxford

Roessler PG. 1987. UDPglucose pyrophosphorylase activity in the diatom Cyclotella cryptica: pathway of chrysolaminarin biosynthesis. Journal of Phycology 23: 494498 
Sadovskaya I, A Souissi, S Souissi, T Grard, P Lencel, CM Greene, S Duin, PS Dmitrenok, AO Chizhov, AS Shashkov \& AI Usov. 2014. Chemical structure and biological activity of a highly branched $(1 \rightarrow 3,1 \rightarrow 6)-\beta-d-$ glucan from Isochrysis galbana. Carbohydrate Polymers 111: $139-148$.

Sforza E, R Cipriani, T Morosinotto, A Bertucco \& GM Giacometti. 2012. Excess $\mathrm{CO}_{2}$ supply inhibits mixotrophic growth of Chlorella protothecoides and Nannochloropsis salina. Bioresource Technology 104: 523-529.

Shematek EM \& E Cabib. 1980. Biosynthesis of the yeast cell wall. II. Regulation of $\beta-(1 \rightarrow 3)$-Glucan synthetase by ATP and GTP. Journal of Biological Chemistry 255: 895902.

Shematek EM, JA Braatz \& E Cabib. 1980. Biosynthesis of the yeast cell wall. I. Preparation and properties of $\beta-(1 \rightarrow 3)$ Glucan synthetase. Journal of Biological Chemistry 255: 888894.

Skov J, PW Kania, L Holten-Andersen, B Fouz \& K Buchmann. 2012. Immunomodulatory effects of dietary $\beta$ 1,3-glucan from Euglena gracilis in rainbow trout (Oncorhynchus mykiss) immersion vaccinated against Yersinia ruckeri. Fish \& Shellfish Immunology 33: 111-120.

Sletmoen M \& BT Stokke. 2008. Higher order structure of $(1,3)-\beta$-D-glucans and its influence on their biological activities and complexation abilities. Biopolymers 89: 310-321.

Stier H, V Ebbeskotte \& J Gruenwald. 2014. Immunemodulatory effects of dietary Yeast Beta-1,3/1,6-D-glucan. Nutrition Journal 13(1): 1-17.

Stoddart RW. 1984. The biosynthesis of polysaccharides, 354 pp. Croom Helm. Beckenham.

Stone BA. 2009. Chemistry of $\beta$-glucans. In: Bacic A, GB Fincher \& BA Stone (eds). Chemistry, biochemistry, and biology of $1 \rightarrow 3-\beta$-Glucans and related polysaccharides, $\mathrm{pp}$. 5-46. Elsevier, Burlington.

Stone BA \& AE Clarke. 1992. Chemistry and biology of $(1 \rightarrow 3)$ $\beta$-Glucans, 803 pp. La Trobe University Press, Victoria.

Sukenik A, J Bennett \& P Falkowski. 1987. Lightsaturated photosynthesis - limitation by electron transport or carbon fixation. Biochimica et Biophysica Acta -Bioenergetics 891: 205-215.

Szaniszlo PJ, MS Kang \& E Cabib. 1985. Stimulation of $\beta$ $(1 \rightarrow 3)$-Glucan synthetase of various fungi by nucleoside triphosphates: generalized regulatory mechanism for cell wall biosynthesis. Journal of Bacteriology 161: 1188-1194.

Tada R, F Ikeda, K Aoki, M Yoshikawa, Y Kato, Y Adachi, A Tanioka, K Ishibashi, K Tsubaki \& N Ohno. 2009. Barley-derived $\beta$-D-glucan induces immunostimulation via a dectin-1-mediated pathway. Immunology Letters 123: 144148.

Tyler BM, S Tripathy, XM Zhang, P Dehal, RHY Jiang, A Aerts, FD Arredondo, L Baxter, D Bensasson, JL Beynon, J Chapman, CMB Damasceno, AE Dorrance,
DL Dou, AW Dickerman, IL Dubchak, M Garbelotto, M Gijzen, SG Gordon, F Govers, NJ Grunwald, W Huang, KL Ivors, RW Jones, S Kamoun, K Krampis, KH Lamour, MK Lee, WH McDonald, M Medina, HJG Meijer, EK Nordberg, DJ Maclean, MD OspinaGiraldo, PF Morris, V Phuntumart, NH Putnam, S Rash, JKC Rose, Y Sakihama, AA Salamov, A Savidor, CF Scheuring, BM Smith, BWS Sobral, A Terry, TA TortoAlalibo, J Win, ZY Xu, HB Zhang, IV Grigoriev, DS Rokhsar \& JL Boore. 2006. Phytophthora genome sequences uncover evolutionary origins and mechanisms of pathogenesis. Science 313(5791): 1261-1266.

Usov AI \& ND Zelinsky. 2013. Chemical structures of algal polysaccharides. In: Dominguez H (ed). Functional ingredients from algae for foods and nutraceuticals, pp. 2386. Woodhead Publishing Limited, Sawston.

Valenzuela A, R Valenzuela, J Sanhueza \& G Morales. 2014. Alimentos funcionales, nutraceúticos y foshu: ¿vamos hacia un nuevo concepto de alimentación? Revista Chilena de Nutrición 41(2): 198-204.

Van den Hoek C, DC Mann \& HM Jahns. 1995. Algae: An introduction to phycology, 627 pp. Cambridge University Press, Cambridge.

Van Wagenen J, TW Miller, S Hobbs, P Hook, B Crowe \& M Huesemann. 2012. Effects of light and temperature on fatty acid production in Nannochloropsis salina. Energies 5(3): 731-740.

Varum KM \& S Myklestad. 1984. Effects of light, salinity and nutrient limitation on the production of $\beta$-1,3-D-glucan and exo-D-glucanase activity in Skeletonema costatum (Grev.) Cleve. Journal of Experimental Marine Biology and Ecology 83: 13-25.

Vetvicka V \& J Vetvickova. 2010. Beta 1,3-glucan: silver bullet or hot air? Open Glycoscience 3: 1-6.

Vetvicka V \& J Vetvickova. 2011. $\beta(1-3)$-D-glucan affects adipogenesis, wound healing and inflammation. Oriental Pharmacy and Experimental Medicine 11: 169-175.

Vieler A, G Wu, C-H Tsai, B Bullard, AJ Cornish, C Harvey, I-B Reca, C Thornburg, R Achawanantakun, CJ Buehl, MS Campbell, D Cavalier, KL Childs, TJ Clark, R Deshpande, E Erickson, AA Ferguson, W Handee, Q Kong, X Li, B Liu, S Lundback, C Peng, RL Roston, Sanjaya, JP Simpson, A Terbush, J Warakanont, S Zäuner, EM Farre, EL Hegg, N Jiang, MH Kuo, Y Lu, KK Niyogi, J Ohlrogge, KW Osteryoung, Y ShacharHill, BB Sears, Y Sun, H Takahashi, M Yandell, SH Shiu \& C Benning. 2012. Genome, functional gene annotation, and nuclear transformation of the heterokont oleaginous alga Nannochloropsis oceanica CCMP1779. PLoS GeneT 8(11): e1003064.

Wan M, P Liu, J Xia, JN Rosenberg, GA Oyler, MJ Betenbaugh, Z Nie \& G Qiu. 2011. The effect of mixotrophy on microalgal growth, lipid content, and expression levels of three pathway genes in Chlorella sorokiniana. Applied Microbiology and Biotechnology 91: 835-844. 
Wang D, K Ning, J Li, J Hu, D Han, H Wang, X Zeng, X Jing, Q Zhou, X Su, X Chang, A Wang, W Wang, J Jia, L Wei, Y Xin, Y Qiao, R Huang, J Chen, B Han, K Yoon, RT Hill, Y Zohar, F Chen, Q Hu \& J Xu. 2014. Nannochloropsis genomes reveal evolution of microalgal oleaginous traits. PLoS GeneT 10(1): e1004094. <http:// dx.doi.org/10.1371/journal.pgen.1004094>

Waterkeyn L \& A Bienfait. 1987. Localisation et role des $\beta$ 1,3-glucanes (callose et chrysolaminarine) dans le genre Pinnularia (Diatomées). La Cellule 74: 198-226.

Werner GH. 1987. Prospective views on unexplored pathways of inmunostimulation. In: Azuma I \& G Jolles (eds). Inmunostimulants: Now and tomorrow, pp. 207-215. Japan Scientific Societies Press, Tokyo / Springer Verlag, Berlin.

Xia S, B Gao, A Li, J Xiong, Z Ao \& C Zhang. 2014. Preliminary characterization, antioxidant properties and production of chrysolaminarin from marine diatom Odontella aurita. Marine Drugs 12(9): 4883-4897.

Xia Y, V Vetvicka, J Yan, M Hanikyrova, T Mayadas \& GD Ross. 1999. The $\beta$-glucan-binding lectin site of mouse CR3 $(\mathrm{CD} 11 \mathrm{~b} / \mathrm{CD} 18)$ and its function in generating a primed state of the receptor that mediates cytotoxic activation in response to iC3b-opsonized target cells. Journal of Immunology 162: 2281-2290.

Xu C, J Lv, YM Lo, SW Cui, X Hu \& M Fan. 2013. Effects of oat $\beta$-glucan on endurance exercise and its anti-fatigue properties in trained rats. Carbohydrate Polymers 92(2): 11591165.
Xu F, Z Cai, W Cong \& F Ouyang. 2004a. Growth and fatty acid composition of Nannochloropsis sp. grown mixotrophically in fed-batch culture. Biotechnology Letters 26: $1319-1322$

Xu F, HH Hu, W Cong, ZL Cai \& F Ouyang. 2004b. Growth characteristics and eicosapentaenoic acid production by Nannochloropsis sp. in mixotrophic conditions. Biotechnology Letters 26: 51-53.

Yangüez K, C Lovazzano, L Contreras-Porcia \& $\mathbf{N}$ Ehrenfeld. 2015. Response to oxidative stress induced by high light and carbon dioxide $\left(\mathrm{CO}_{2}\right)$ in the biodiesel producer model Nannochloropsis salina (Ochrophyta, Eustigmatales). Revista de Biología Marina y Oceanografía 50 S1: 163-175.

Yen HW, IC Hu, CY Chen \& JS Chang. 2014. Design of photobioreactors for algal cultivation. In: Pandey A, L DuuJong, Y Chisti \& CR Soccol (eds). Biofuels from algae, pp. 23-45. Elsevier, Burlington.

Zekovic DB, S Kwiatkowski, MM Vrvic, D Jakovljevic \& CA Moran. 2005. Natural and modified $(1 \rightarrow 3)-\beta-D-$ Glucans in health promotion and disease alleviation. Critical Reviews in Biotechnology 25: 205-230.

Zhang Y, S Li, X Wang, L Zhang \& PC Cheung. 2011. Advances in lentinan: isolation, structure, chain conformation and bioactivities. Food Hydrocolloids 25: 196-206. 